\title{
Binuclear Fluoro-bridged Zinc and Cadmium Complexes of a Schiff-Base Expanded Porphyrin: Fluoride Abstraction from the Tetrafluoroborate Anion
}

\author{
Elisa Tomat, Luciano Cuesta, Vincent M. Lynch and Jonathan L. Sessler* \\ Department of Chemistry and Biochemistry
}

The University of Texas at Austin,

1 University Station A5300

Austin, Texas, 78712-0165.

\section{General experimental procedures}

Prior to use, all glassware was soaked in KOH-saturated isopropyl alcohol for ca. $12 \mathrm{~h}$ and then rinsed with water and acetone before being thoroughly dried. Tetrahydrofuran (THF) and diethyl ether were dried by passage through two columns of activated alumina. Acetone was purchased from Fisher Scientific and used as received. Deuterated solvents were purchased from Cambridge Isotope Labs and used as received. The starting metal complex, $\mathrm{Zn}\left(\mathrm{BF}_{4}\right)_{2} \cdot 5 \mathrm{H}_{2} \mathrm{O}$, was purchased commercially (Strem) and used as received. The starting $\left[\mathrm{Cd}_{2}(\mathrm{THF})_{5}\right]\left(\mathrm{BF}_{4}\right)_{4}$ complex was prepared following reported procedures. ${ }^{1}$ Solutions were stirred magnetically.

Nuclear magnetic resonance (NMR) spectra were obtained on a Varian Mercury $400 \mathrm{MHz}$ or on a Varian Inova $500 \mathrm{MHz}$. High-resolution mass spectra were obtained at the University of Texas at Austin, Department of Chemistry and Biochemistry, Mass Spectrometry Facility.

\section{Synthetic details}

Bis-Zn(II) complex 2, [( $\left.\left.\mathbf{C}_{38} \mathbf{H}_{36} \mathbf{N}_{8}\right) \mathbf{Z n}_{2} \mathbf{F}_{2}\left(\mathrm{BF}_{4}\right)_{2}\right]$ : Macrocycle 1a in its free base form (81.0 $\mathrm{mg}, 0.134 \mathrm{mmol})$ was suspended in dry THF $(30 \mathrm{~mL})$ under an argon atmosphere. Upon addition of $\mathrm{Zn}\left(\mathrm{BF}_{4}\right)_{2} \cdot 5 \mathrm{H}_{2} \mathrm{O}(70.4 \mathrm{mg}, 0.295 \mathrm{mmol})$, the yellow slurry became a bright orange solution. The reaction mixture was stirred under argon for 3 hours and then concentrated under reduced pressure to precipitate a pale orange solid. After filtration, the crude powder obtained in this way was dissolved in a minimal amount of acetone and then placed in a freezer $\left(-20^{\circ} \mathrm{C}\right)$ overnight. This yielded $71 \mathrm{mg}$ of 2 as yellow crystals (56\% yield). ${ }^{1} \mathrm{H}$ NMR ( $400 \mathrm{MHz}, 296 \mathrm{~K}$, DMSO- $\left.d_{6}\right): \delta 11.96(\mathrm{~s}, 2 \mathrm{H}, \mathrm{NH}), 11.56(\mathrm{~s}, 2 \mathrm{H}, \mathrm{NH}), 8.80(\mathrm{~s}, 4 \mathrm{H}, \mathrm{CHN}), 7.65$ (br s, 4H, ArH), 7.37 (br s, 4H, ArH), 7.22 (br s, 4H, pyrrolic $\mathrm{CH}$ ), 6.49 (br s, 4H, pyrrolic $\mathrm{CH}), 1.89$ (s, 12H, $\left.\mathrm{CH}_{3}\right) .{ }^{13} \mathrm{C}$ NMR $\left(100 \mathrm{MHz}, 296 \mathrm{~K}\right.$, DMSO- $\left.d_{6}\right): \delta 178.70,148.00,147.50,142.97,132.98$, $132.72,127.81,125.05,120.70,118.18,113.29,111.75,107.72,36.56,36.07,27.86,27.60$, 27.26, 26.81. ${ }^{19} \mathrm{~F}$ NMR $\left(200 \mathrm{MHz}, 296 \mathrm{~K}\right.$, DMSO- $\left.d_{6}\right):-154.5$. CI-MS: $\left[\mathrm{M}-\mathrm{H}-2 \mathrm{~F}-2\left(\mathrm{BF}_{4}\right)\right]^{+} \mathrm{m} / \mathrm{z}$ 735; HR CI-MS: : $\left[\mathrm{M}-\mathrm{H}-2 \mathrm{~F}-2\left(\mathrm{BF}_{4}\right)\right]^{+} m / z 735.148048$ (calc. for $\mathrm{C}_{38} \mathrm{H}_{35} \mathrm{~N}_{8}{ }^{66} \mathrm{Zn}_{2}$ : 735.150539). ES-MS: $\left[\mathrm{M}-\mathrm{F}-2\left(\mathrm{BF}_{4}\right)\right]^{+} \mathrm{m} / z$ 751. Anal. Calcd. $\left[\mathrm{C}_{38} \mathrm{H}_{36} \mathrm{~B}_{2} \mathrm{~F}_{10} \mathrm{~N}_{8} \mathrm{Zn}_{2}\right] \cdot 2 / 5$ (THF): C, 51.14; $\mathrm{H}$, 5.01; N, 9.94. Found: C, 51.33; H,4.87; N.9.48. 
Bis-Cd(II) complex 3, [( $\left.\left.\mathrm{C}_{42} \mathrm{H}_{44} \mathbf{N}_{8} \mathbf{O}_{4}\right) \mathbf{C d}_{2} \mathbf{F}_{2}\left(\mathrm{BF}_{4}\right)_{2}\right]$ : The free base form of macrocycle $\mathbf{1 b}$ (80.0 $\mathrm{mg}, 0.110 \mathrm{mmol})$ and $\left[\mathrm{Cd}_{2}(\mathrm{THF})_{5}\right]\left(\mathrm{BF}_{4}\right)_{4}(113.0 \mathrm{mg}, 0.121 \mathrm{mmol})$ were mixed in dry THF (30 $\mathrm{mL}$ ). The resulting suspension was then stirred under argon 3 hours to give an orange solution. This solution was then concentrated under reduced pressure leading to formation of an orange precipitate. After collection by filtration, the solids, containing the crude product $\mathbf{3}$, were redissolved in a minimal amount of acetone and then layered with diethyl ether. After storing overnight at $-20^{\circ} \mathrm{C}, 86 \mathrm{mg}$ of 3 was isolated as yellow crystals (54\% yield). ${ }^{1} \mathrm{H}$ NMR ( $400 \mathrm{MHz}$, $296 \mathrm{~K}$, acetone- $\left.d_{6}\right): \delta 11.65(\mathrm{~s}, 4 \mathrm{H}, \mathrm{NH}), 9.21(\mathrm{~s}, 4 \mathrm{H}, \mathrm{CHN}), 7.79(\mathrm{~s}, 4 \mathrm{H}, \mathrm{ArH}), 7.51(\mathrm{br} \mathrm{s}, 4 \mathrm{H}$, pyrrolic $\mathrm{CH}), 6.89$ (br s, $4 \mathrm{H}$, pyrrolic $\mathrm{CH}), 4.34\left(\mathrm{~s}, 12 \mathrm{H}, \mathrm{OCH}_{3}\right) 1.73\left(\mathrm{~s}, 12 \mathrm{H}, \mathrm{CH}_{3}\right) .{ }^{1} \mathrm{H}$ NMR $\left(400 \mathrm{MHz}, 296 \mathrm{~K}, \mathrm{DMSO}-d_{6}\right): 8.59$ (s, 4H, CHN), 7.16 (s, 4H, ArH), 6.83 (br s, 4H, pyrrolic $\mathrm{CH}), 6.32$ (br s, $4 \mathrm{H}$, pyrrolic $\mathrm{CH}), 3.77\left(\mathrm{~s}, 12 \mathrm{H}, \mathrm{OCH}_{3}\right) 1.74\left(\mathrm{~s}, 12 \mathrm{H}, \mathrm{CH}_{3}\right)(\mathrm{NH}$ resonances not observed). ${ }^{19} \mathrm{~F}$ NMR $\left(200 \mathrm{MHz}, 296 \mathrm{~K}, \mathrm{DMSO}-d_{6}\right)$ : -154.5. ES-MS: $[\mathrm{M}-2 \mathrm{CdF}]^{+} \mathrm{m} / \mathrm{z} 725$. Anal. Calcd. $\left[\mathrm{C}_{42} \mathrm{H}_{44} \mathrm{~B}_{2} \mathrm{~F}_{10} \mathrm{~N}_{8} \mathrm{O}_{4} \mathrm{Cd}_{2}\right] \cdot 3 \mathrm{H}_{2} \mathrm{O}: \mathrm{C}, 41.51 ; \mathrm{H}, 4.15 ; \mathrm{N}, 9.22$. Found: $\mathrm{C}, 41.43 ; \mathrm{H}, 4.03$; N.9.61.

\section{X-ray experimental}

The data were collected on a Nonius Kappa CCD diffractometer using a graphite monochromator with MoK $\alpha$ radiation $(\lambda=0.71073 \AA)$. Data collections were conducted at 153 $\mathrm{K}$ using an Oxford Cryostream low temperature device. Data reductions were performed using DENZO-SMN. ${ }^{2}$ The structures were solved by direct methods using SIR97 $7^{3}$ and refined by fullmatrix least-squares on $\mathrm{F}^{2}$ with anisotropic displacement parameters for the non- $\mathrm{H}$ atoms using SHELXL-97. ${ }^{4}$

The following definitions apply to all refinements carried out in the context of this study:

$\mathrm{R}=\Sigma\left(\left|\mathrm{F}_{0}\right|-\left|\mathrm{F}_{\mathrm{c}}\right|\right) / \Sigma\left|\mathrm{F}_{0}\right|$ for reflections with $\mathrm{F}_{0}>4\left(\Sigma\left(\mathrm{F}_{0}\right)\right)$,

$\mathrm{R}_{\mathrm{W}}=\left\{\Sigma \mathrm{w}\left(\left|\mathrm{F}_{0}\right|^{2}-\left|\mathrm{F}_{\mathrm{c}}\right|^{2}\right)^{2} / \Sigma \mathrm{w}\left|\mathrm{F}_{0}\right|^{4}\right\}^{1 / 2}$, where $\mathrm{w}$ is the weight given each reflection,

Goodness of fit, $\mathrm{S}=\left[\Sigma \mathrm{w}\left(\left|\mathrm{F}_{0}\right|^{2}-\left|\mathrm{F}_{\mathrm{c}}\right|^{2}\right)^{2} /(n-p)\right]^{1 / 2}$,

where $n$ is the number of reflections and $p$ is the number of refined parameters.

Unless otherwise specified, hydrogen atoms were calculated in ideal positions with isotropic displacement parameters set to $1.2 \times$ Ueq of the attached atom $(1.5 \times$ Ueq for methyl hydrogen atoms). Neutral atom scattering factors and values used to calculate the linear absorption coefficients are from the International Tables for X-ray Crystallography. ${ }^{5}$

Bis-Zn(II) complex 2, $\left[\left(\mathbf{C}_{38} \mathbf{H}_{36} \mathbf{N}_{8}\right) \mathbf{Z n}_{2} \mathbf{F}_{2}\left(\mathrm{BF}_{4}\right)_{2}\right] \cdot\left(\mathbf{C}_{3} \mathbf{H}_{6} \mathbf{O}\right)_{3}$ : Crystals grew as yellow plates by slow evaporation from acetone. A total of 333 frames of data were collected using $\omega$-scans with a scan range of $1^{\circ}$ and a counting time of 238 seconds per frame. Details of crystal, data collection and structure refinement are listed in Table S1.

The complex lies around a crystallographic two-fold rotation axis at $1 / 2, y, 1 / 2$. Z' equals $1 / 2$. The two Zn-tetrafluoroborate ion pairs, as well as the coordinating oxygen atom of the acetone molecule, are disordered about two orientations of equal weight (see Figure S1). The site occupancy factor for the pair of $\mathrm{Zn}$ ions were determined by setting the site occupancy of one ion, $\mathrm{Zn} 1$, to equal the variable $\mathrm{x}$ and the site occupancy factor for the other orientation, designated as Zn1a, equal to (1-x). Both ions were allowed to refine isotropically. The isotropic displacement parameter for the two ions was constrained to be equal. The site occupancy factors refined to a value very close to $1 / 2$. In subsequent refinements, a site 
occupancy of $1 / 2$ was used for both ions. The geometry of the tetrafluoroborate anions were restrained to be equivalent throughout the refinement. The site occupancy factors for the atoms of the anion were set to $1 / 2$ to match that of the $\mathrm{Zn}$ ions to which they are bound. Ultimately, the $\mathrm{Zn}$ ions and the atoms of the anion were refined anisotropically. Their anisotropic displacement parameters were restrained to be approximately isotropic in the final stages of the refinement. The function, $\Sigma \mathrm{w}\left(\left|\mathrm{F}_{\mathrm{O}}\right|^{2}-\left|\mathrm{F}_{\mathrm{c}}\right|^{2}\right)^{2}$, was minimized, where $\mathrm{w}=1 /\left[\left(\sigma\left(\mathrm{F}_{\mathrm{O}}\right)\right)^{2}+(0.02 * \mathrm{P})^{2}+(27.8554\right.$ $* \mathrm{P})]$ and $\mathrm{P}=\left(\left|\mathrm{F}_{\mathrm{O}}\right|^{2}+2\left|\mathrm{~F}_{\mathrm{c}}\right|^{2}\right) / 3 . \quad \mathrm{R}_{\mathrm{W}}\left(\mathrm{F}^{2}\right)$ refined to 0.157 , with $\mathrm{R}(\mathrm{F})$ equal to 0.0705 and a goodness of fit, $\mathrm{S}$, of 1.22 .

The data were corrected for secondary extinction effects. The correction takes the form: $\mathrm{F}_{\text {corr }}=\mathrm{kF}_{\mathrm{c}} /\left[1+\left(1.2(2) \times 10^{-6}\right) * \mathrm{~F}_{\mathrm{c}}^{2} \lambda^{3} /(\sin 2 \theta)\right]^{0.25}$ where $\mathrm{k}$ is the overall scale factor.

Bis-Cd(II) complex 3, $\left[\left(\mathrm{C}_{42} \mathrm{H}_{44} \mathrm{~N}_{8} \mathrm{O}_{4}\right) \mathrm{Cd}_{2} \mathrm{~F}_{2}\left(\mathrm{BF}_{4}\right)_{2}\right] \cdot\left(\mathrm{H}_{2} \mathrm{O}\right)_{3}\left(\mathrm{C}_{3} \mathrm{H}_{6} \mathrm{O}\right)_{4}$ : Crystals grew as yellow lathes by slow diffusion of diethyl ether into a concentrated solution of $\mathbf{3}$ in acetone. A total of 368 frames of data were collected using $\omega$-scans with a scan range of $0.7^{\circ}$ and a counting time of 150 seconds per frame. Details of crystal data, data collection and structure refinement are listed in Table S1.

The hydrogen atoms on the water molecules were initially located in a $\Delta \mathrm{F}$ map. The function, $\Sigma \mathrm{w}\left(\left|\mathrm{F}_{\mathrm{O}}\right|^{2}-\left|\mathrm{F}_{\mathrm{c}}\right|^{2}\right)^{2}$, was minimized, where $\mathrm{w}=1 /\left[\left(\sigma\left(\mathrm{F}_{\mathrm{o}}\right)\right)^{2}+(0.0473 * \mathrm{P})^{2}+(15.0 * \mathrm{P})\right]$ and $\mathrm{P}=\left(\left|\mathrm{F}_{\mathrm{o}}\right|^{2}+2\left|\mathrm{~F}_{\mathrm{c}}\right|^{2}\right) / 3$. $\mathrm{R}_{\mathrm{W}}\left(\mathrm{F}^{2}\right)$ refined to 0.175 , with $\mathrm{R}(\mathrm{F})$ equal to 0.0682 and a goodness of fit, $\mathrm{S},=1.10$. The data were corrected for secondary extinction effects. The correction takes the form: $\mathrm{F}_{\text {corr }}=\mathrm{kF}_{\mathrm{c}} /\left[1+\left(2.2(3) \times 10^{-6}\right)^{*} \mathrm{~F}_{\mathrm{c}}{ }^{2} \lambda^{3} /(\sin 2 \theta)\right]^{0.25}$ where $\mathrm{k}$ is the overall scale factor. 
Table S1 Crystal data and structure refinement parameters for complexes $\mathbf{2}$ and $\mathbf{3}$.

\begin{tabular}{|c|c|c|}
\hline & 2 & 3 \\
\hline \multirow{2}{*}{ empirical formula } & $\mathrm{C}_{47} \mathrm{H}_{54} \mathrm{~B}_{2} \mathrm{~F}_{10} \mathrm{~N}_{8} \mathrm{O}_{3} \mathrm{Zn}_{2}$ & $\mathrm{C}_{54} \mathrm{H}_{74} \mathrm{~B}_{2} \mathrm{Cd}_{2} \mathrm{~F}_{10} \mathrm{~N}_{8} \mathrm{O}_{11}$ \\
\hline & $\mathbf{2} \cdot\left(\mathrm{CH}_{3} \mathrm{COCH}_{3}\right)_{3}$ & 3. $\left(\mathrm{H}_{2} \mathrm{O}\right)_{3}\left(\mathrm{CH}_{3} \mathrm{COCH}_{3}\right)_{4}$ \\
\hline formula weight & 1121.34 & 1447.63 \\
\hline crystal system & monoclinic & triclinic \\
\hline space group & $\mathrm{C} 2 / \mathrm{c}$ & P-1 \\
\hline$a, \AA$ & $27.6016(3)$ & $13.811(1)$ \\
\hline$b, \AA$ & $10.8804(2)$ & $15.527(1)$ \\
\hline$c, \AA$ & $20.1887(3)$ & $16.203(1)$ \\
\hline$\alpha,{ }^{\circ}$ & 90 & $101.226(2)$ \\
\hline$\beta,^{\circ}$ & $126.536(1)$ & $106.446(2)$ \\
\hline$\gamma,{ }^{\circ}$ & 90 & $92.269(2)$ \\
\hline $\mathrm{V}, \AA^{3}$ & $4871.51(13)$ & $3252.1(4)$ \\
\hline Z & 4 & 2 \\
\hline$D\left(\right.$ Calc'd $^{\prime}, \mathrm{mg} / \mathrm{m}^{3}$ & 1.529 & 1.478 \\
\hline abs. coeff., $\mathrm{mm}^{-1}$ & 1.074 & 0.742 \\
\hline$F(000)$ & 2304 & 1476 \\
\hline crystal size, $\mathrm{mm}$ & $0.27 \times 0.25 \times 0.12$ & $0.20 \times 0.10 \times 0.06$ \\
\hline$\theta$ for data collection, ${ }^{\circ}$ & $2.92-27.47$ & $2.09-25.00$ \\
\hline \multirow[t]{3}{*}{ limiting indices } & $-35 \leq \mathrm{h} \leq 35$ & $-16 \leq \mathrm{h} \leq 15$ \\
\hline & $-14 \leq \mathrm{k} \leq 12$ & $-18 \leq \mathrm{k} \leq 16$ \\
\hline & $-26 \leq 1 \leq 26$ & $-18 \leq 1 \leq 19$ \\
\hline reflections collected & 9640 & 17044 \\
\hline independent reflections & 5574 & 11209 \\
\hline completeness to $\theta_{\max }$ & $99.8 \%$ & $97.9 \%$ \\
\hline absorption correction & none & none \\
\hline data/restraints/parameters & $5574 / 166 / 385$ & $11209 / 0 / 801$ \\
\hline goodness-of-fit on $\mathrm{F}^{2}$ & 1.184 & 1.100 \\
\hline $\mathrm{R}, \mathrm{R}_{\mathrm{w}}$ & $0.0705,0.1481$ & $0.0682,0.1502$ \\
\hline
\end{tabular}




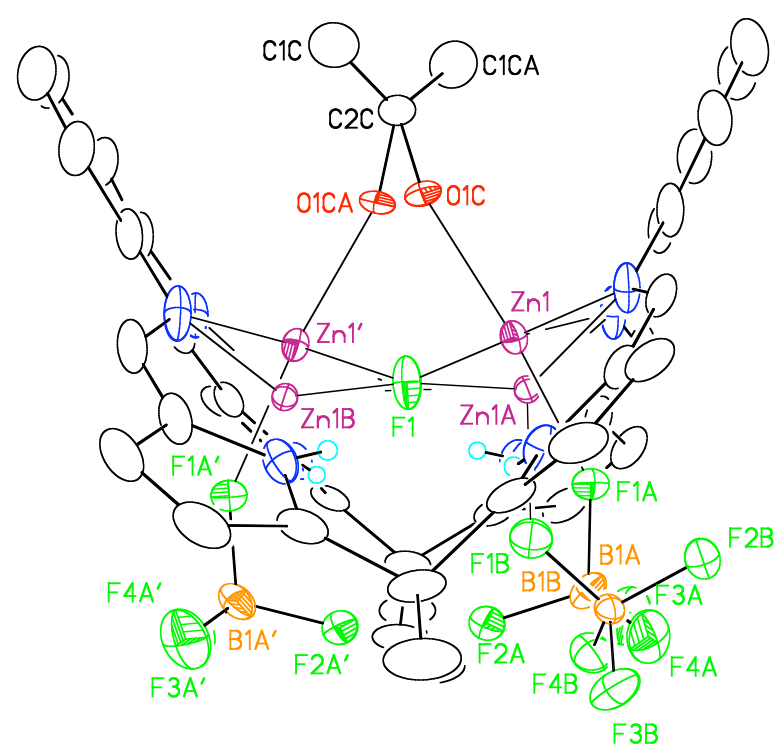

Figure S1 View of $\mathrm{Zn}$ complex 2 showing the disorder of the $\left[\mathrm{Zn}\left(\mathrm{BF}_{4}\right)\right]^{+}$ion pairs and the coordinated acetone molecule. Displacement ellipsoids are scaled to the $50 \%$ probability level. Most hydrogen atoms have been removed for clarity. The macrocycle lies on a crystallographic two-fold rotation axis at $1 / 2, y, 3 / 4$. Atoms with labels appended by a ' are related by $1-\mathrm{x}, \mathrm{y}, 3 / 2-\mathrm{z}$.

\section{References}

(1) Reger, D. L.; Collins, J. E. Inorg. Synth. 2004, 34, 91.

(2) Otwinowski, Z.; Minor, W. In Methods in Enzymology, Macromolecular Crystallography, Pt. A 1997; Vol. 276, p 307-326

(3) Altomare, A.; Burla, M. C.; Camalli, M.; Cascarano, G. L.; Giacovazzo, C.; Guagliardi, A.; Moliterni, A. G. G.; Polidori, G.; Spagna, R. J. Appl. Crystallogr. 1999, 32, 115-119.

(4) Sheldrick, G. M. SHELXL97. Program for the Refinement of Crystal Structures; University of Gottingen: Germany, 1994.

(5) International Tables for X-ray Crystallography; Kluwer Academic Press: Boston, 1992; Vol. C, Tables 4.2.6.8 and 6.1.1.4. 